ärdl. Halbkugel: Häufigkeit 30 ; mittl. Breife -7.8

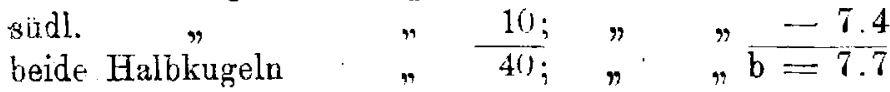

Die Beobachtung der Protuberanzen ergab in der Mitte des Sommers mehrere interessante Fälle, indem es gelungen ist, zu beobachten, wie entfernt von der Sonnenoberfläche Protuberauzen entstanden. Die Neu= bildungen begannen an der Grenze eines am Sonnenrande befindlicken dunkleren segmentes und waren meist senkrecht gegen diese Begrenzung gerichtet. Ein spezieller Bericht ist in den Monatsberichten der Akad. d. Wiss. (Berlin November) zu finden. Für die beobachteten Fälle ist als Erklärung anzunehmen, dass durch chemische Prozesse entfernt von der Sonnenoberfläche der leuchtende Zustand hervorgebracht ist.

Potsdam, 1879, Jan. 16.

Prof. Dr. Spoever.

\title{
Ueber einen neuen Veränderlichen.
}

Ich nabe die Ehre Ihnen mitzutheilen, dass der Sterm der Durchmusterung

$$
\begin{aligned}
& 21^{219 m} 25^{5} \\
& +67^{0} 49^{\prime} 5 \text { mag. } 9.2
\end{aligned}
$$

verinderlich ist, was man vielleicht noch nicht bemerkt jat. Der Stern ist $\mathrm{Nr}$. 14 meiner photometrischen Gruppe e (Ann. de l'Obs. de Moscou Vol. IV. livr. 2). Die photometrischen Vergleichungen mit den Sternen Nr. $12,13,15, q$ derselben Gruppe und blosse Schätzungen haben folgendes ergeben:

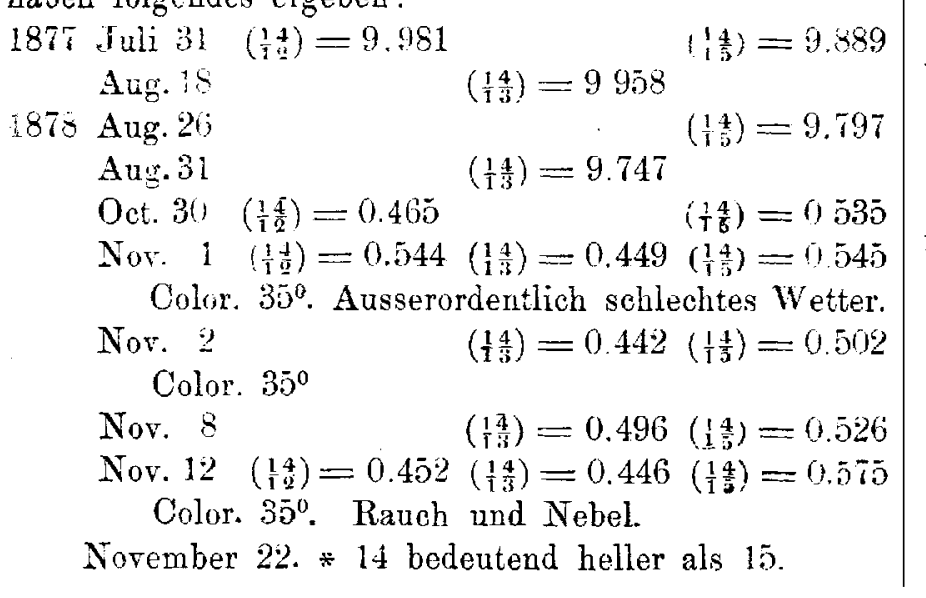

December 28. Der Helligkeit nach steht der Stern in der Mitte zwischen 15 und $g$.

1879 Januar 2. Die Helligkeit hat noch mehr. scheint es, abgenommen.

Januar 16. Der Stern ist so hell wie $\%$

$$
\left(\begin{array}{c}
1 \\
15
\end{array}\right) 9.511 \text { (nabe) }
$$

Die angegebenen Kablen sind die Logarithmen der relativen Helligkeiten. Im Jahro 1877 ist der Stern als ,röthlich" bezeichnet (Aun. pag. 48), im Nov. 1878 sah ich den Stern von so rother Färbung, dass ich das Colorimeter zu verstellem genöthigt war, was aberhaupt zum ersten $\mathrm{Hal}$ bei meinen Beobachtungen geschelien ist.

Die Oerter und Grössen der Fergleichsterne sind nach Durchmusterung:

$$
\begin{array}{rrrr}
12 . & 21 \mathrm{~h} 10 \mathrm{~m}, 5 & -690506 & \text { Mag. } 6.8 \\
13 . & 12.11 & 69.26 .7 & 6.5 \\
15 . & 5.45 & 67.39 .9 & 7.0 \\
\text { q. } & 7.35 & 67.54 .4 & 8.7
\end{array}
$$

Moskau, 1879 , Januar $5 / 17$.

\section{W. Ceraski,}

Observator der Sternwarte.

\section{Anzeige.}

Zu Kauf gesucht ein ca. $3^{\prime \prime}$ parall. aufgest. Tubus. sowie ein desgl. Cometensucher. Off. unt. K. P. 453. beford. Haasenstein \& Vogler, Berlin S.W.

\section{In halt:}

$Z_{11}$ Nr. 2243. C. Bruhns. Mittheilungen von Planetenbeobachtungen. 16r. - C. E. Doolittie. Observations of Jupiter's Satellites made at the Sayre Observatory. I7I. - Sfoerer. Beobacbtungen der Sonnenfecken etc. I73. -- W. Ceraski. Ueber einen neuen Veränderlicheu. 175. - Anzeige. 175 . 